\title{
Efflux of Macromolecules from Washed Dictyostelium discoideum
}

\author{
BY M. I. KRICHEVSKY AND L. L. LOVE \\ U.S. Department of Health, Education, and Welfare, Public Health \\ Service, National Institutes of Health, National Institute of \\ Dental Research, Bethesda, Maryland 20014 U.S.A.
}

(Received 3 August 1965)

\section{SUMMARY}

Dilution of washed Dictyostelium discoideum amoebae in distilled water leads to an essentially immediate and specific efflux of RNA and protein into the extracellular environment. A substance's ability to prevent leakage correlates with its ability to stimulate the rate of morphogenesis.

\section{INTRODUCTION}

As a result of studying the mechanism by which imidazole compounds affect the rate of morphogenesis in Dictyostelium discoideum, it was postulated that the site of action was at the cell surface or outside the amoebae (Krichevsky \& Love, 1964a). One possibility by which such a postulated site could control the rate of development is through controlling the passage of materials across the cell membrane. Thus, it might be expected that compounds which stimulated the rate of morphogenesis could inhibit the leakage of intracellular components into the medium. The present report describes the ability of various stimulatory materials to decrease the efflux of specific macromolecular constituents from washed amoebae.

\section{METHODS}

The procedures for growing and harvesting the myxamoebae were described previously (Krichevsky \& Wright, 1963). For each incubation mixture, the amoebae from one cookie sheet $(15 \times 10 \mathrm{in}$.) of solid growth medium were harvested just before complete ingestion of bacterial growth, washed free from residual Escherichia coli and finally suspended in distilled water to a final volume of $5 \mathrm{ml}$. Each incubation mixture had $4.8 \mathrm{ml}$. of the suspended amoebae in $48 \mathrm{ml}$. final volume. The incubations were done in standard $1 \mathrm{l}$. beakers on a six-place magnetic stirrer so that all suspensions were stirred at identical rates at ambient temperature (about $\mathbf{2 2}^{\circ}$ ).

Cell-free filtrates of the incubation mixtures were obtained by vacuum filtration of $2 \mathrm{ml}$. samples using Millipore filters of pore size $0.45 \mu$ and $47 \mathrm{~mm}$. diameter (Millipore Filter Corporation, Bedford, Mass.; catalogue number HAWPO 4700)

Pentose-containing materials were assayed by the orcinol reaction of Mejbaum as modified by Horecker, Smyrniotis \& Klenow (1953). Protein was determined by the method of Sutherland, Cori, Haynes \& Olsen (1949). The ninhydrin assay 
for amino acids was done by the procedure of Rosen (1957). Diphenylamine reacting materials were determined as described by Dische (1955). Nucleic acids were isolated by the procedure of Szybalska \& Szybalski (1962) except that the cell-free filtrates were not treated with sodium lauryl sulphate before $\mathrm{NaCl}$ addition.

\section{RESULTS}

Preliminary experiments had indicated that assaying cell-free filtrates from the suspensions for their content of ultraviolet-absorbing materials provided a convenient method for testing the postulate that stimulants of development could

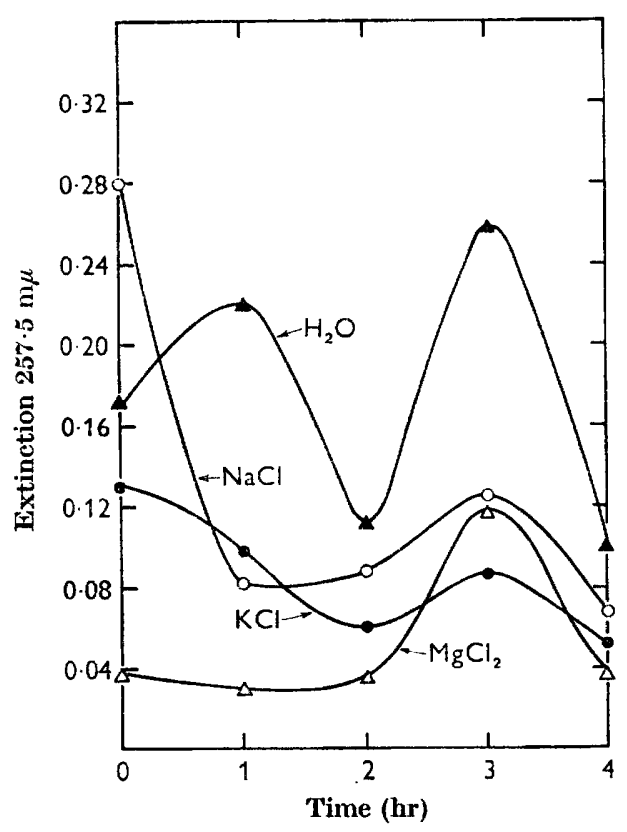

Fig. 1

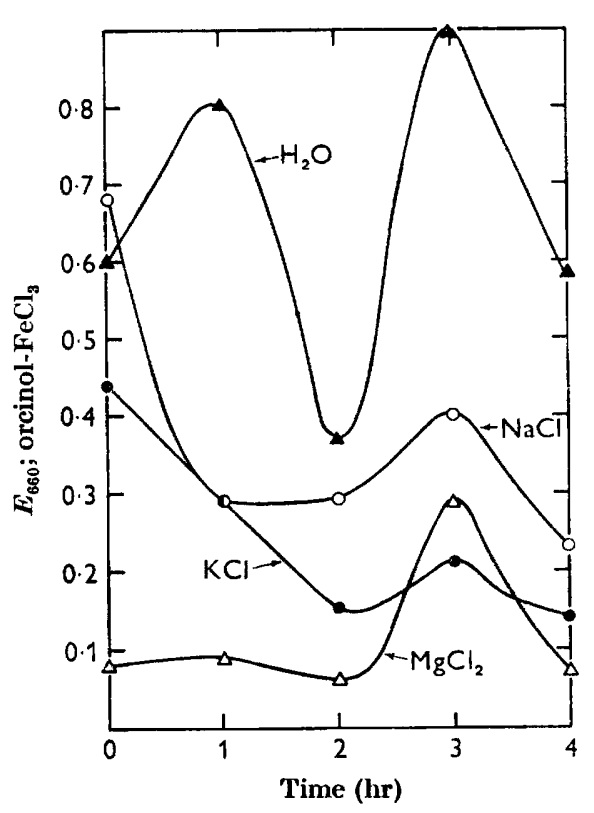

Fig. 2

Fig. 1. The leakage of u.v.-absorbing materials in the presence of chloride salts. Amoebae were incubated in water $(\Delta-\Delta) ; 0.01 \mathrm{M}-\mathrm{NaCl}(\mathrm{O}-\mathrm{O}) ; 0.01 \mathrm{M}-\mathrm{KCl}(0-0)$; or $0.005 \mathrm{M}$ $\mathrm{MgCl}_{2}(\times-\times)$. With $0.5 \mathrm{M}-\mathrm{NaOH}$, a $1 / 20$ dilution, of the cell-free filtrate was made of the incubation mixtures noted above at $0,1,2,3,4 \mathrm{hr}$. The extinction of a $1 \mathrm{~cm}$ thick sample was determined at $257.5 \mathrm{~m} \mu$.

Fig. 2. The leakage of pentose-containing materials in the presence of chloride salts. Amoebae were incubated in water $(\Delta-\Delta) ; 0.01 \mathrm{M}-\mathrm{NaCl}(\mathrm{O}-\mathrm{O}) ; 0.1 \mathrm{M}-\mathrm{KCl}(\mathbf{0}-0)$; or 0.005 $\mathbf{M}-\mathrm{MgCl}_{2}(x-\times)$. To $0.5 \mathrm{ml}$. samples of cell-free filtrates of each incubation mixture were added $0.5 \mathrm{ml}$. of $6 \%$ perchloric acid. The samples were centrifuged and the supernatant separated and retained. Both the precipitates and supernatant solutions were assayed for total pentose. Only the results of the precipitate assays are presented in this figure.

control leakage from the organisms. An example of the data is illustrated in Fig. 1. The u.v.-absorbing material found in the cellular environment was, for the most part, greatest in the case of the medium containing only water, next was $0.01 \mathrm{M}-$ $\mathrm{NaCl}$, then $0.01 \mathrm{M}-\mathrm{KCl}$, and least was $0.005 \mathrm{M}-\mathrm{MgCl}_{2}$. The most striking departure from this ranking may be seen in the 'zero time' samples for water and $\mathrm{NaCl}$. Since 
the amoebae were added to the suspending medium and the suspension was filtered, the earliest samples obtained are not true initial samples but of the order of 2- to 4-minutes samples. Therefore, the release of the u.v.-absorbing material must have occurred within that period.

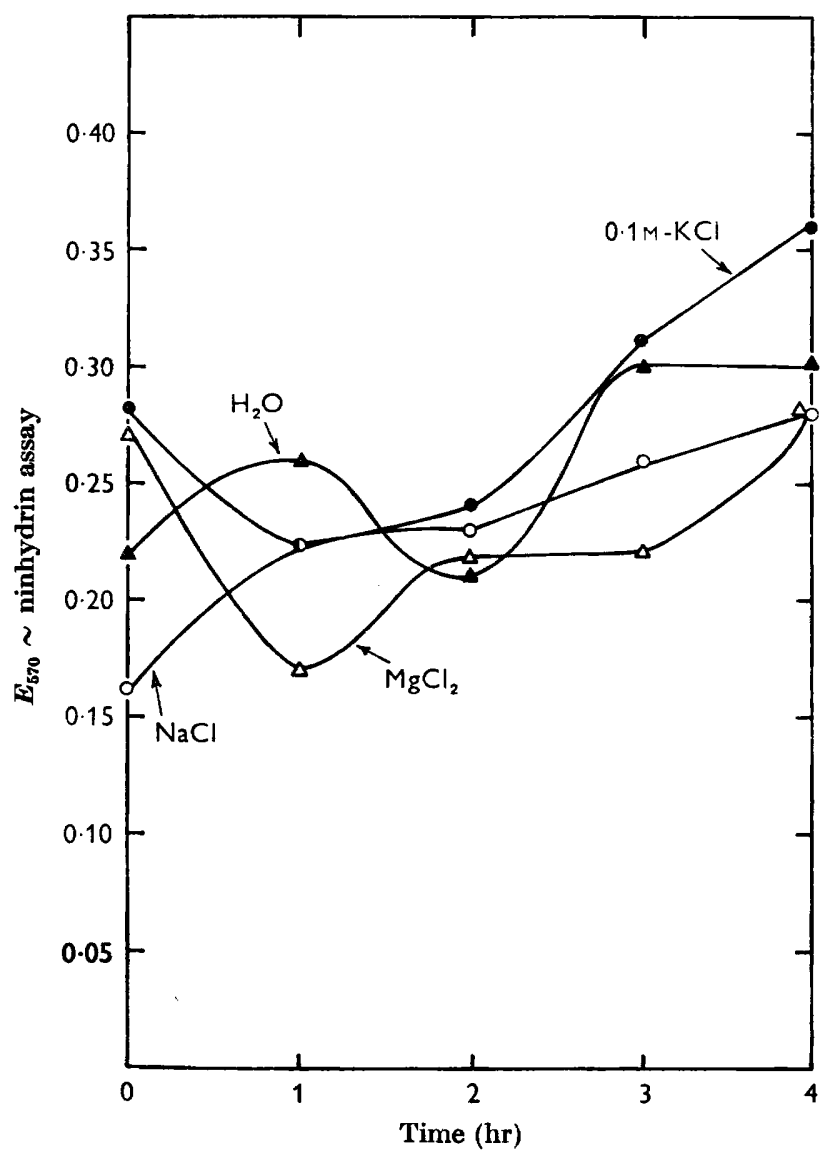

Fig. 3. The leakage of ninhydrin-reactive materials in the presence of chloride salts. Amoebae were incubated in water $(\Delta-\Delta) ; 0.01 \mathrm{M}-\mathrm{NaCl}(\mathrm{O}-\mathrm{O}) ; 0.01 \mathrm{M}-\mathrm{KCl}(\mathrm{O}-\mathrm{O})$; or 0.005 $\mathrm{M}^{-\mathrm{MgCl}_{2}}(x-\times)$. To $0,1,2,3$ and $4 \mathrm{hr}$ samples of cell-free filtrates of the above incubation mixtures were added equal volumes of $0.5 \mathrm{~m}-\mathrm{NaOH}$. One-tenth $\mathrm{ml}$. of the diluted samples were assayed for their content of ninhydrin-reactive material.

The spectrum of various samples exhibited an absorption maximum at about $260 \mathrm{~m} \mu$. In preliminary experiments, the material appeared to be precipitable by cold perchloric acid. Therefore, the samples described in Fig. 1 were tested for their pentose content see Fig. 2. The qualitative relationship between the u.v.-absorbing material in the cell-free filtrate as a whole and in the perchloric acid-precipitable, pentose-containing material was consistently close (Fig. 1 vs. Fig. 2). Thus, in the experiments to be described below, the u.v.-absorption data were always obtained but will be omitted with the understanding that they were qualitatively the same as the pentose assay data. 
When the perchloric acid-soluble fractions from the experiment shown in Figs. 1 and 2 were assayed for pentose content, it was found that there was little or no significant difference with either time or treatment. Furthermore, the values were all low, i.e. on the order of E0.04 to 0.06 in most of the cases (the range was 0.02 to 0.09 ).

To ascertain whether the release of materials into the medium was a generalized phenomenon, the experiment in Fig. 3 was performed. In this case, the cellfree filtrates were assayed for their content of ninhydrin-positive material. It may be seen that these materials were released in an entirely different manner than the pentose-reacting material. No differences in amounts of the ninhydring-reacting material could be attributed to the nature of the suspending medium.


Fig. 4. The pentose and protein contents of cell-free filtrates in the presence of $L-$ histidine. Amoebae were incubated in water $(\Delta-\Delta) ; 0.04 \mathrm{M}-\mathrm{L}$-histidine, pH $5(0-0)$; or L-histidine, pH 7 (O-O). Samples were taken for pentose determinations as described for Fig. 2. Instead of the final centrifugation, the samples were filtered on $25 \mathrm{~mm}$ Millipore filters (type HA). The precipitates were redissolved in $1 \mathrm{ml}$. of $0.25 \mathrm{M}-\mathrm{NaOH}$ and assayed as usual (shown on the left).

The same procedure was used to obtain the samples for protein assay, except that the perchlorate-treated samples were placed in a boiling water bath for $15 \mathrm{~min}$., cooled, filtered and redissolved in $0.3 \mathrm{ml}, 0.5 \mathrm{M}-\mathrm{NaOH}$. The results of the protein assays are shown on the right.

The effect of L-histidine on the leakage of macromolecules from washed amoebae is illustrated in Fig. 4. When supplied at pH 5, L-histidine markedly decreased the amount of perchloric acid precipitable material found in the cell-free filtrate as compared to either distilled water or $\mathrm{L}$-histidine supplied at $\mathrm{pH} 7$. The foregoing result was qualitatively the same whether the assay procedure used was for pentose or protein material. However, the kinetics and the quantitative relationships were found to differ in detail.

Figure 5 depicts the results of substituting D-histidine for the L-isomer. As in the previous experiment, $\mathrm{D}$-histidine at $\mathrm{pH} 5$ was more effective in preventing the efflux of macromolecular constituents from the amoebae than was either water or $\mathrm{D}$-histidine at $\mathrm{pH} 7$. 
The effects due to sodium phosphate buffers were complex (Fig. 6). Initially, pH 7 sodium phosphate buffer was incapable of preventing the leakage of pentosecontaining material as compared with distilled water. When the $\mathrm{pH}$ of the phos-
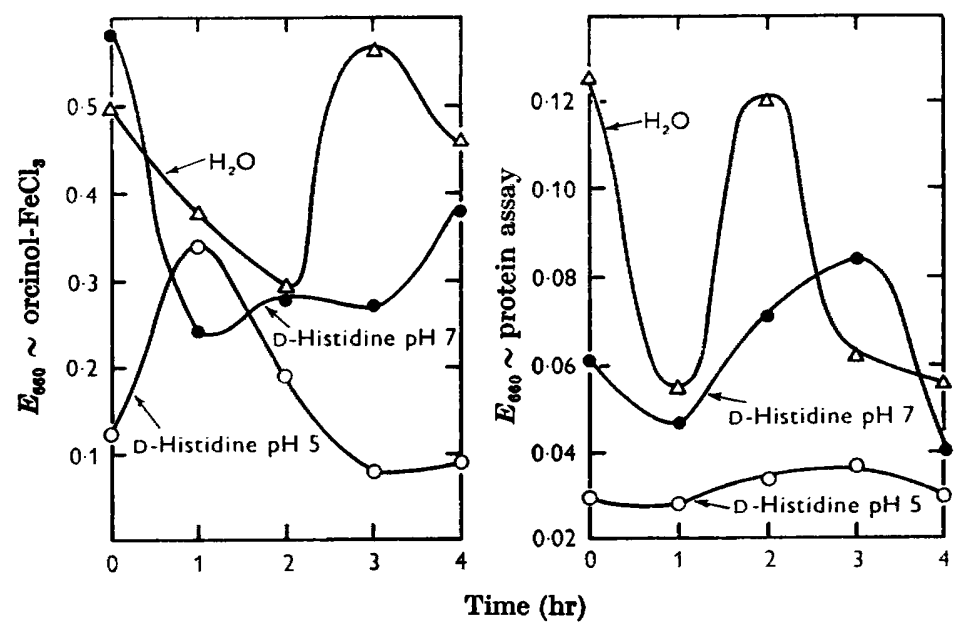

Fig. 5. The pentose and protein leakage from cells incubated in D-histidine. All condiditions were the same as those described for Fig. 4 except that D-histidine was used in place of L-histidine.
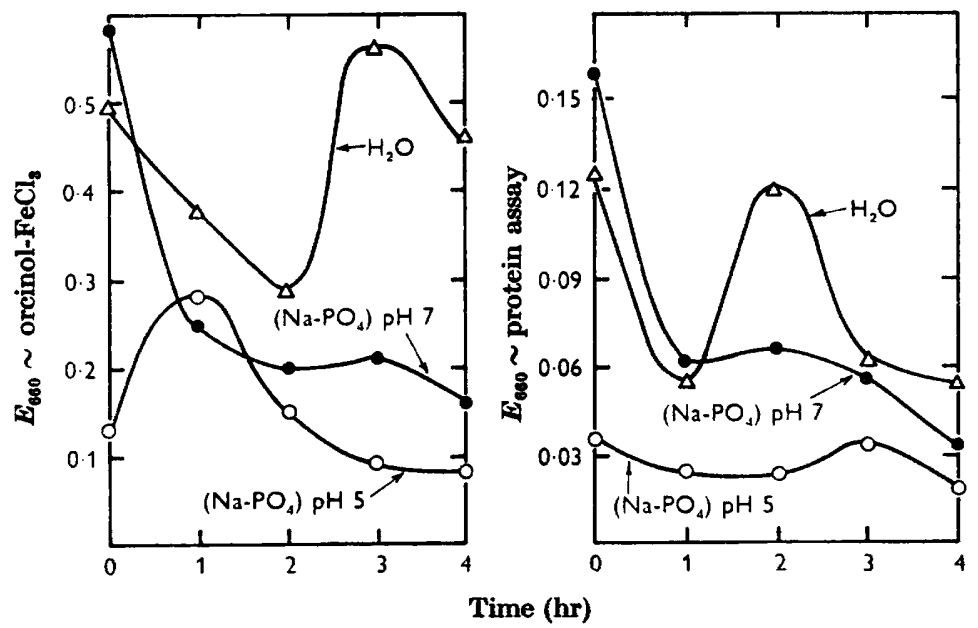

Fig. 6. The pentose and protein leakage from cells incubated in (sodium) phosphate buffer. All conditions were the same as those described for Fig. 4 except that $0.01 \mathrm{~m}$ (sodium) phosphate buffers were substituted for the L-histidine.

phate was 5.0 there was a marked lowering of extracellular pentose-containing material found throughout the sample period. It may be seen that the effect of the hydrogen ion concentration of the suspending medium was less important with the passage of time. In contrast, the $\mathrm{pH}$ of the sodium phosphate medium exerted a greater effect on protein leakage. Since the buffer was adjusted to a constant 
phosphate concentration, the effects noted above may have been due to the increased sodium concentration as opposed to any $\mathrm{pH}$ effect (e.g. see Fig. 2).

In order to assess the significance of the leakage of the materials to the total system, the data for the incubation of amoebae in distilled water from four separate experiments were combined as shown in Fig. 7. It may be seen that as much as

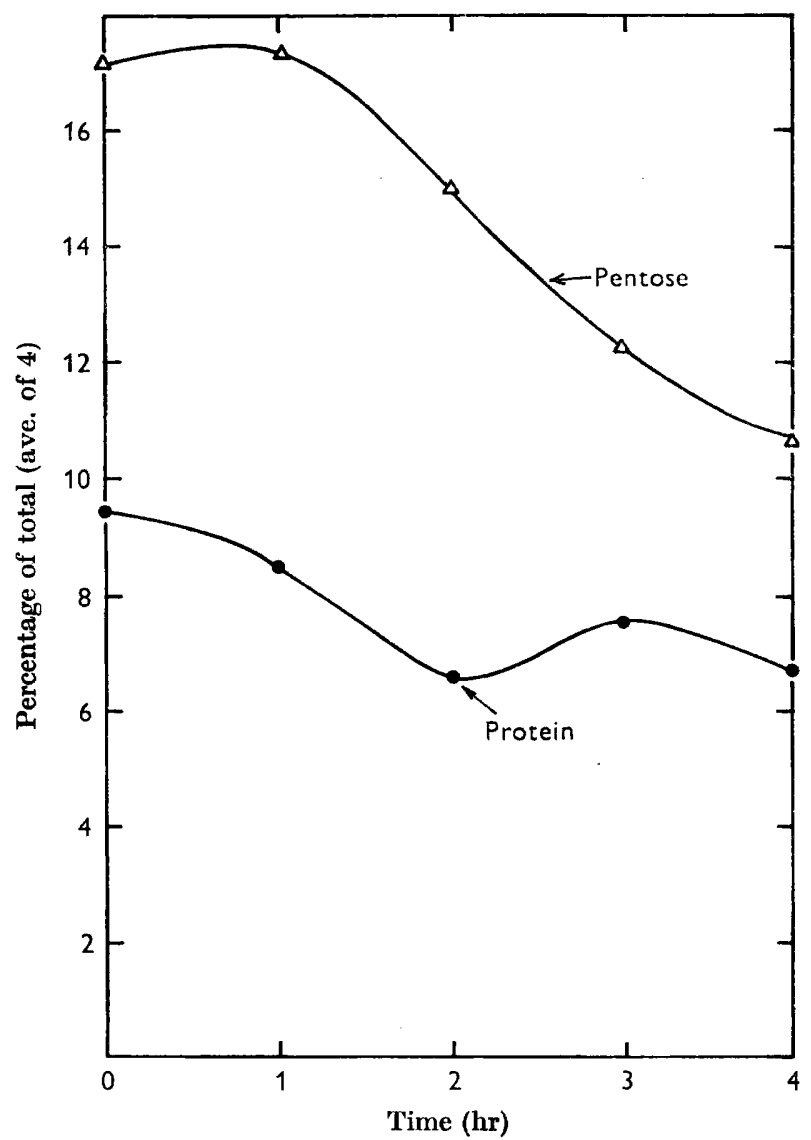

Fig. 7. The proportions of macromolecular leakage from amoebae incubated in distilled water. The data shown in this figure are the averages of four different experiments performed as described in Fig. 4. The incubation medium was distilled water in all cases. The values for the total amount of pentose and protein reacting materials were obtained by taking a second initial sample and omitting the filtration step so that the cellular contents were included in the samples. The appropriate assays were performed on $1 / 10$ dilutions.

$17 \%$ of the perchloric acid-insoluble pentose-reacting material contained in the amoebae leaked into the medium (the range of all samples being 6.4-26.4\%). In the case of protein the high average was also the earlier and was about $9.5 \%$ (range $0 \cdot 8$ $15.0 \%$ ). The likelihood of the extracellular amounts of the two types of macromolecules being correlated with time, was tested by determining the correlation coefficients of each of the four experiments separately and by pooling the data within the individual experiments and determining the over-all correlation coefficient. The 
values found were: $0.96,0.49,0.63$, and 0.97 for the individual experiments and 0.665 for the pooled data. In two out of the four experiments here considered the correlation coefficients were highly significant $(P \leqslant 0 \cdot 01)$ though the number of observations was very small for each group. Furthermore, the pooled value indicates that the correlation of the two factors (i.e. extracellular amounts of protein and pentose-containing materials at the various times) is significant also $(P \leqslant 0.01)$.

The pentose-containing perchloric acid-precipitable material was partially characterized as follows: first, the yield of orcinol reactive material extruded from amoebae in suspension in water or $0.04 \mathrm{M}-\mathrm{L}$-histidine (at $\mathrm{pH} 7$ ), was compared with that obtained by perchloric acid-precipitation or ethanolic precipitation. In all samples the yields were approximately the same regardless of the method of sample preparation. Little or no diphenylamine reactive material was isolated by either of the above procedures even though the samples for assay were increased by a factor of five. In addition, the material isolated by ethanolic precipitation exhibited similar spectral properties to commercial yeast RNA, with a $260 / 280 \mathrm{~m} \mu$ ratio of approximately $2 \cdot 03$ to $2 \cdot 15$ in various samples.

\section{DISCUSSION}

The data presented here indicate that when washed amoebae from the growing amoeboid stage of Dictyostelium discoideum are diluted in distilled water, there is an immediate and specific efflux of macromolecules from the amoebae into the medium. The types of macromolecules concerned are ribosenucleic acid and protein. Deoxyribonucleic acid (as diphenylamine reactive material) was not detected in the cell filtrates. Low molecular weight ninhydrin-positive materials leaked into the medium in the same way, irrespective of the nature of the medium.

The leakage phenomenon could not be ascribed to simple osmotic shock. This is indicated by the observation that compounds at approximately equivalent tonicities varied widely in their capacity to prevent the leakage. When the suspending fluid was L-histidine at $\mathrm{pH} 5 \cdot 0$, the efflux of RNA and protein was almost completely prevented. In contrast, when the L-histidine was adjusted to $\mathrm{pH} 7 \cdot 0$, the leakage was as great and often greater than that found when distilled water was the diluent. Another example is provided by the series $\mathrm{NaCl}, \mathrm{KCl}$, and $\mathrm{MgCl}_{2}$. Although the ionic strength of the $\mathrm{MgCl}_{2}$ solution was less than that of the other two salts, it was by far the most effective in preventing leakage.

Continuing incubation of cell suspensions after the initial efflux of macromolecules (in those permitting leakage) for the most part resulted in either an over-all smooth lowering of the extracellular amounts or, an oscillation of these. The oscillation consisted of an initial drop in level followed by a secondary rise. The changes in RNA and protein with the passage of time were probably not random and independent phenomena. This was indicated by the statistical analysis of the replicate incubations wherein water alone was the suspending medium. It may be speculated that the change in extracellular amounts of RNA and protein are under cellular control. If the changes were due to extracellular destruction (in the cases where lowering was observed) it seems unlikely that the amounts of the two types of macromolecules would be so well correlated.

The data presented here suggest that the ability of various materials to stimulate 
the over-all rate of morphogenesis in Dictyostelium discoideum is correlated with their prevention of leakage of RNA and protein from the amoeboid cells under the test conditions. In the series of chloride salts tested, $\mathrm{NaCl}$ was only slightly stimulatory, $\mathrm{KCl}$ more so and $\mathrm{MgCl}_{2}$ very stimulatory (Krichevsky \& Wright, 1963). As shown in Figs. 1 and 2, the same ranking obtained with respect to the ability of these salts in preventing the efflux of RNA. At pH 5, L-histidine is both a stimulant of the rate of morphogenesis (Krichevsky \& Wright, 1963; Krichevsky \& Love, $1964 a, b)$ and an inhibitor of macromolecular leakage; at $\mathrm{pH} \mathrm{7,} \mathrm{it} \mathrm{is} \mathrm{neither.} \mathrm{Although}$ not as striking, the results were similar with $\mathrm{D}$-histidine and sodium phosphate buffers.

Thus, materials which stimulate the rate of differentiation seem indeed capable of action at the surface of the cell. It may be postulated that the RNA and protein which leak from the amoebae are not indispensable for cellular differentiation, but provide stimulatory intermediates through their catabolism to monomeric constituents, and this only when available inside the organism. Certainly, it is well documented (Wright, 1964) that endogenous RNA and protein are degraded during morphogenesis.

\section{REFERENCES}

Dische, Z. (1955). In The Nucleic Acids. Ed. by E. Chargaff \& J. N. Davidson. Vol. 1. New York: Academic Press.

Horecker, B. L. Smyrniotis, P. Z. \& Kuenow, H. (1953). The formation of sedoheptulose phosphate from pentose phosphate. J. biol. Chem. 205, 661 .

Krichevsky, M. I. \& Love, L. L. (1964a). The uptake and utilization of histidine by washed amoebae in the course of development in Dictyostelium discoideum. J. gen. Microbiol. 34, 483.

Krichevsky, M. I. \& Love, L. L. (1964b). Adenine inhibition of the rate of sorocarp formation in Dictyostelium discoideum. J. gen. Microbiol. 37, 293.

Krichevsky, M. I. \& Wright, B. E. (1963). Environmental control of the course of development in Dictyostelium discoideum. J. gen. Microbiol. 32, 195.

Rosen, H. (1957). A modified ninhydrin colorimetric analysis for amino acids. Arch. Biochem. Biophys. 67, 10.

Sutherland, E. W., Cori, C. F., Haynes, R. \& Olsen, N. S. (1949). Purification of the hyperglycemic-glycogenolytic factor from insulin and from gastric mucosa. $J$. biol. Chem. 180, 825.

Szybalska, E. H. \& Szybalski, W. (1962). Genetics of human cell lines, IV. DNAmediated heritablet ransformation of a biochemical trait. Proc. natn. Acad. Sci., U.S.A. 48, 2026.

Wright, B. E. (1964). In Biochemistry and Physiology of Protozoa. Ed. by S. H. Hutner. Vol. 3. New York: Academic Press. 